\title{
Incidence of Keratinophilic Fungi from Selected Soils of Vidarbha Region of Maharashtra State, India
}

\author{
Sunil Kumar Deshmukh and Shilpa Amit Verekar \\ Department of Natural Products, Piramal Enterprises Limited, 1 Nirlon Complex, Off Western Express Highway, Near NSE Complex, \\ Goregaon (East), Mumbai 400 063, India
}

Correspondence should be addressed to Sunil Kumar Deshmukh; sunild2811@rediffmail.com

Received 14 July 2014; Accepted 5 October 2014; Published 10 November 2014

Academic Editor: Daniel Elad

Copyright (c) 2014 S. K. Deshmukh and S. A. Verekar. This is an open access article distributed under the Creative Commons Attribution License, which permits unrestricted use, distribution, and reproduction in any medium, provided the original work is properly cited.

\begin{abstract}
One hundred and fifty samples were collected from eleven districts of Vidarbha region of Maharashtra state and screened for the presence of keratinophilic fungi using hair baiting technique for isolation. Seventy-one isolates were recovered and identified. The cultures were identified using macro- and micromorphological features. Their identification was also confirmed by the BLAST search of sequences of the ITS1-5.8S-ITS2 rDNA region against the NCBI/Genbank data and compared with deposited sequences for identification purpose. Thirteen species of eight genera were isolated, namely, Auxarthron conjugatum (2.00\%), Chrysosporium indicum (14.00\%), Chrysosporium evolceanui (2.66\%), Chrysosporium tropicum (4.66\%), Chrysosporium zonatum (1.33\%), Chrysosporium state of Ctenomyces serratus (3.33\%), Gymnascella dankaliensis (1.33\%), Gymnascella hyalinospora (0.66\%), Gymnoascoideus petalosporus (0.66\%), Microsporum gypseum complex (9.33\%), Trichophyton mentagrophytes (2.00\%), T. terrestre (3.33\%), and Uncinocarpus queenslandicus $(2.00 \%)$. This study indicates that the soils of Vidarbha region of Maharashtra may be significant reservoirs of certain keratinophilic fungi.
\end{abstract}

\section{Introduction}

Keratinophilic fungi are an ecologically important group of fungi that decompose one of the most abundant and highly stable animal proteins on earth-keratin which they utilize as a nutrient substrate for growth. The distribution of these fungi depends on different factors, one of which, of vital importance, is human and/or animal presence [1]. Some of these fungi are well-known dermatophytes and are known to cause superficial cutaneous infections (dermatophytoses) of keratinized tissues (skin, hair, and nails) of humans and animals. Mycotic infection is reported throughout the world, and it is extremely contagious [2]. The occurrence of dermatophytes in soil was reported for the first time by Vanbreuseghem [3] using the hair bait technique. Since then studies on the isolation of keratinophilic fungi from soil have been investigated throughout the world [4-7]. Vidarbha is the eastern region of Maharashtra state which lies between $17^{\circ} 57^{\prime}-21^{\circ} 46^{\prime} \mathrm{N}$ latitude and $75^{\circ} 57^{\prime}-80^{\circ} 59^{\prime} \mathrm{E}$ longitude. The temperature of Vidarbha ranges from a minimum of $12-25^{\circ} \mathrm{C}$ to a maximum of $30-48^{\circ} \mathrm{C}$ with relative humidity varying from $10-15 \%$ to $60-95 \%$. Tropical climate and topology of Vidarbha region of Maharashtra make this region a potentially interesting area to study the distribution of these fungi. We therefore undertook this study and report the results obtained.

\section{Materials and Methods}

2.1. Collection and Processing of Soil Samples. One hundred and fifty samples were collected from various sites of eleven districts, namely, Akola, Amravati, Bhandara, Buldhana, Chandrapur, Gadchiroli, Gondia, Nagpur, Wardha, Yavatmal, and Washim from Vidhabha region of Maharashtra during June 2009-May 2010 (Figures 1 and 2 and Table 1). The samples were collected from the superficial layer of soil at a depth not exceeding $3-5 \mathrm{~cm}$ with a plastic spoon in sterile polyethylene bags, brought to the laboratory and stored at $15^{\circ} \mathrm{C}$ for a maximum of two weeks if not processed promptly. The samples were collected from forest land, cultivated land, road side, public gardens, poultry farm, cattle farm, garbage, and 


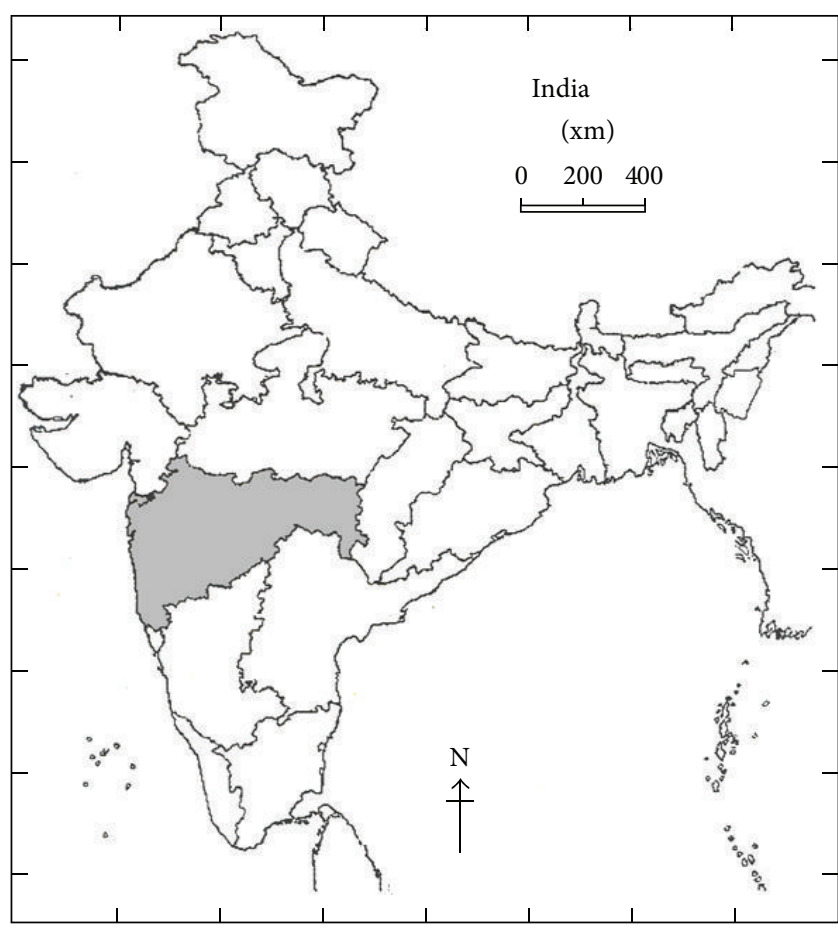

FIGURE 1: Location of the State of Maharashtra in India.

lake side. For isolation, hair bait technique of Vanbreuseghem [3] was used. Sterile Petri dishes were half filled with the soil samples and moistened with water and baited with keratin by burying sterile human hairs in the soil. Human hairs from a 25-years-old male were used. The hairs were washed several times, first with detergent (hair shampoo), followed by water, and then with diethyl ether, and finally autoclaved at $121^{\circ} \mathrm{C}$ for $15 \mathrm{~min}$. The dishes were incubated at room temperature $\left(28^{\circ} \mathrm{C}\right.$ \pm 2 ) and examined daily after 5 days for fungal growth for 4 weeks.

2.2. Isolation and Identification of Keratinophilic Fungi. After observing the growth under a stereoscopic binocular microscope it was cultured on slopes/plates of Sabouraud's dextrose agar supplemented with chloramphenicol $(50 \mathrm{mg} / \mathrm{L})$ and cycloheximide $(500 \mathrm{mg} / \mathrm{L})$. Cultures were incubated at room temperature for five to ten days following which the cultures were microscopically checked for purity and subcultured to get pure cultures. These fungi were identified based on the various available monographs using macro- and micromorphological features of these cultures [8-12].

2.3. Molecular Identification of Keratinophilic Fungi. Molecular characteristics of the cultures were studied by determination of their DNA sequences of the ITS1-5.8S-ITS2 region. Genomic DNA was extracted by the Miniprep protocol of Lee and Taylor [13]. The ITS1-5.8S-ITS2 rDNA was amplified using ITS1 and ITS4 as the forward and reverse primers, respectively, as described by White et al. [14]. Amplification was performed in $100 \mu \mathrm{L}$ reaction volumes containing $10 \mathrm{x}$ buffer $10 \mu \mathrm{L}, \mathrm{MgCl}_{2}(25 \mathrm{mM}) 2 \mu \mathrm{L}$, dNTP $(10 \mathrm{mM}) 2 \mu \mathrm{L}$, ITS1
TABLE 1: Distribution of soil samples examined of Vidarbha region of Maharashtra (India).

\begin{tabular}{lccc}
\hline Districts & $\begin{array}{c}\text { Number of } \\
\text { samples } \\
\text { examined }\end{array}$ & $\begin{array}{c}\text { Number of } \\
\text { positive samples }\end{array}$ & \% positive \\
\hline Akola & 24 & 11 & 45.83 \\
Amravati & 20 & 9 & 45.00 \\
Bhandara & 15 & 8 & 53.33 \\
Buldhana & 15 & 7 & 46.66 \\
Chandrapur & 5 & 2 & 40.00 \\
Gadchiroli & 5 & 2 & 40.00 \\
Gondia & 6 & 4 & 66.66 \\
Nagpur & 15 & 7 & 46.66 \\
Wardha & 15 & 5 & 33.33 \\
Yavatmal & 15 & 8 & 53.33 \\
Washim & 15 & 8 & 53.33 \\
Total & $\mathbf{1 5 0}$ & $\mathbf{7 1}$ & $\mathbf{4 7 . 3 3}$ \\
\hline
\end{tabular}

primer (20 pm) $2 \mu \mathrm{L}$, ITS4 primer (20 pm) $2 \mu \mathrm{L}$, Taq Polymerase $(2.5 \mathrm{U}) 1 \mu \mathrm{L}$, DNA Sample $(5 \mu \mathrm{g} / \mathrm{mL}) 3 \mu \mathrm{L}$, and Milli Q Water $78 \mu \mathrm{L}$. The PCR reaction was carried out using a Thermal Cycler (M.J. research, PTC 200) with conditions as follows: denaturation for five minutes at $94^{\circ} \mathrm{C}, 34$ cycles of (30 sec at $94^{\circ} \mathrm{C}, 30 \mathrm{sec}$ at $55^{\circ} \mathrm{C}$, and $1 \mathrm{~min}$ at $72^{\circ} \mathrm{C}$ ) extension for four minutes at $72^{\circ} \mathrm{C}$ and storage at $4^{\circ} \mathrm{C}$. Negative controls were used in each set of reactions. The final products were analyzed by electrophoresis on $1.2 \%$ agarose (Sigma). The PCR products were purified using Qiagen Gel extraction kit (CAT number 28704) and the PCR products of expected size were sequenced using ITS1 and ITS4 primers in an Applied Biosystem 3730 DNA analyzer at GenOmbiotech, Pune, India.

2.4. Phylogenetic Analysis. Similarity analysis of the nucleotides was performed by BLAST searches against sequences available in GenBank [15]. For phylogenetic tree construction, multiple sequences were obtained from GenBank and the alignments were performed using MEGA6 [16].

\section{Results and Discussion}

The results of the isolations are presented in Table 2. They reveal that out of 150 samples only 71 yielded keratinophilic fungi that can be categorized in thirteen species of eight genera, namely, Auxarthron conjugatum (2.00\%), Chrysosporium indicum (14.00\%), Chrysosporium evolceanui (2.66\%), Chrysosporium tropicum (4.66\%), Chrysosporium zonatum (1.33\%), Chrysosporium state of Ctenomyces serratus (3.33\%), Gymnascella dankaliensis (1.33\%), Gymnascella hyalinospora (0.66\%), Gymnoascoideus petalosporus (0.66\%), Microsporum gypseum complex (9.33\%), Trichophyton mentagrophytes (2.00\%), T. terrestre (3.33\%), and Uncinocarpus queenslandicus $(2.00 \%)$. 


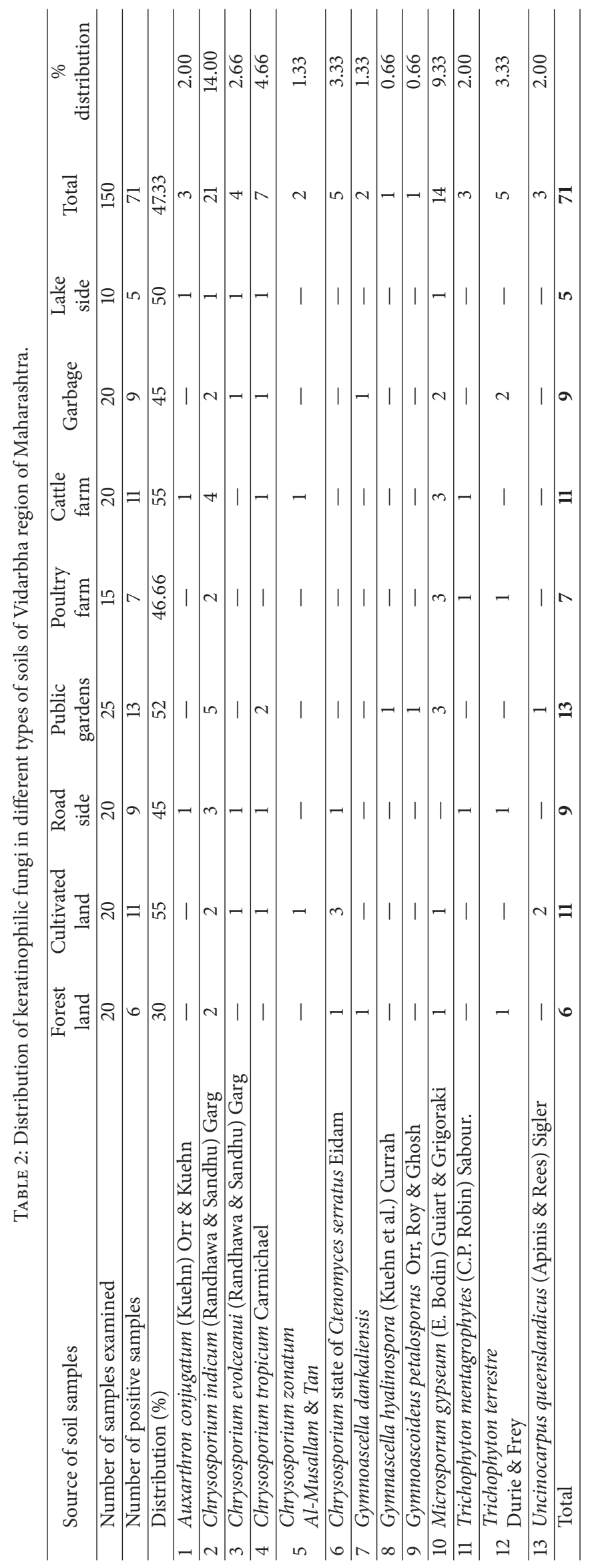




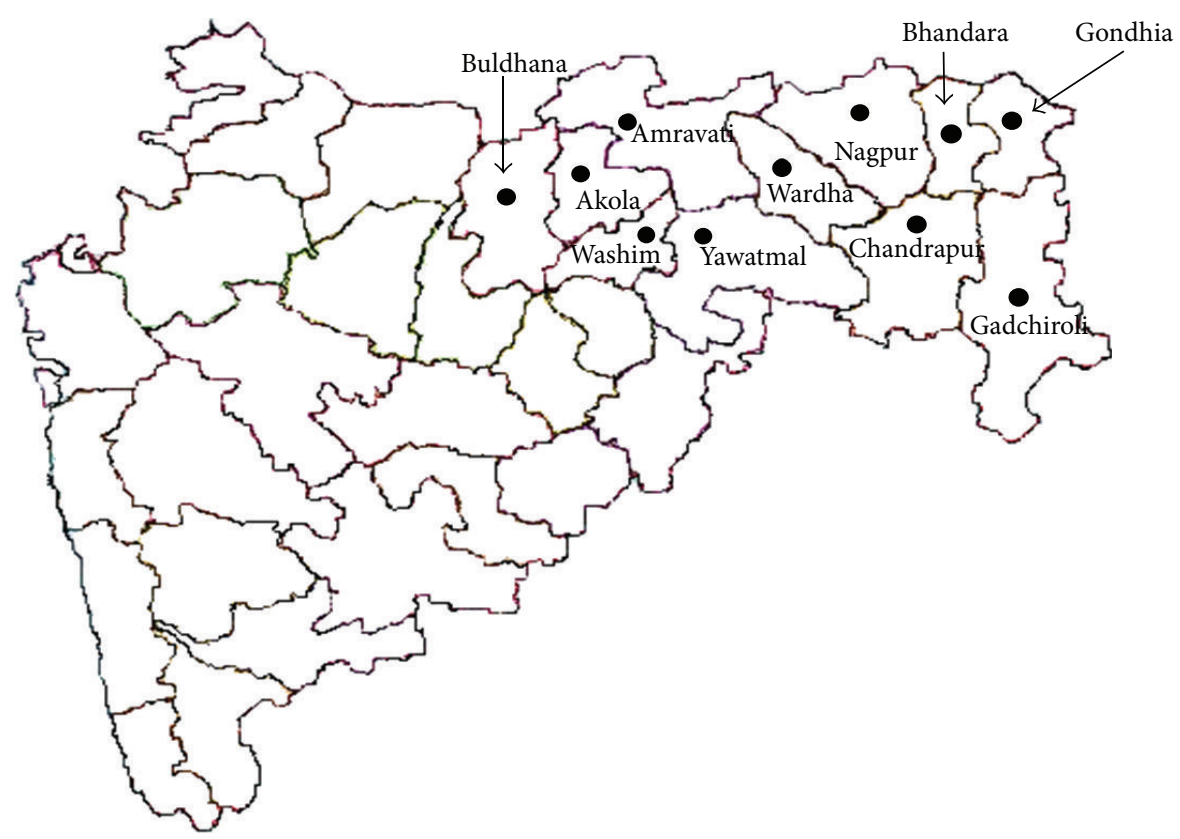

FIGURE 2: Sites of collection of soil samples in Vidarbha region of Maharashtra.

All thirteen strains yielded unique PCR amplification. The sequences of the ITS1-5.8S-ITS2 rDNA region for the thirteen strains were from 527 bp to $631 \mathrm{bp}$. Chrysosporium state of Ctenomyces serratus and Trichophyton mentagrophytes were the smallest and the largest, respectively. The other species showed a product size of approximately $600 \mathrm{bp}$. There was considerable difference in the sequence data of the thirteen strains analyzed. The data were also compared with sequences deposited in the NCBI/Genbank for identification purposes and a tree was constructed with the nearest type of strain sequences based on rRNA gene sequences (ITS region) using the Maximum Composite Likelihood Method (Figure 3). The Phylogenetic tree indicates different clusters for each isolate showing their sequence variation. The sequences obtained show greater than $96 \%$ similarity to the reference sequences available in NCBI Genbank database.

Chrysosporium indicum (14.00\%) was the most prevalent species and this is in agreement with the finding of previous workers [17-20]. Its high percentage of distribution clearly indicates that it is well adapted to warmer condition of India [21]. Microsporum gypseum complex was found next to C. indicum in distribution $(9.33 \%)$ and has been reported from various parts of India. We also encountered Arthroderma sp. three times in association with the Microsporum gypseum complex, which was made up of the two teleomorph states Arthroderma incurvata and A. gypsea, but A. fulva was altogether absent. However, mating experiments were not conducted to confirm its specific identity. It was reported from Indian soils by Dey and Kakoti [22]. It was further isolated from various parts of India [21, 23-27]. Chrysosporium tropicum was next to $M$. gypseum comprising of $4.66 \%$ in distribution. It is a cosmopolitan species and has been reported from various parts of India $[17,18,27,28]$.
The other species of Chrysosporium isolated were Chrysosporium evolceanui (2.66\%), Chrysosporium zonatum (1.33\%), and Chrysosporium state of Ctenomyces serratus (3.33\%). Chrysosporium evolceanui was reported from Indian soils as Trichophyton evolceanui by Randhawa and Sandhu [17]; then Garg [21] placed it in the genus Chrysosporium as C. evolceanui. It is reported from Indian soils $[26,29,30]$. Various workers have isolated Chrysosporium zonatum from Indian soil $[31,32]$. Chrysosporium state of Ctenomyces serratus was recorded in $3.33 \%$ of samples and this has been reported from various parts of India [17-19, 21].

Other species of keratinophilic fungi isolated were Gymnascella dankaliensis (1.33\%), Gymnascella hyalinospora (0.66\%), Gymnoascoideus petalosporus (0.66\%), Auxarthron conjugatum $(2.00 \%)$, and Uncinocarpus queenslandicus $(2.00 \%)$. G. dankailensis is reported from Indian soils [29, 33]. Gymnascella hyalinospora was reported from Indian soils by Singh and Kushwaha [32] and Deshmukh [34]. Gymnoascoideus petalosporus was previously recorded from Chilka Lake soil [35], soils from Vedanthangal Water Bird Sanctuary [20], and soils of Orissa [33]. Auxarthron conjugatum is reported from Indian soils by Deshmukh and Verekar [20], Jain and Agrawal [36], and Deshmukh and Agrawal [37]. Anamorphic state of Uncinocarpus queenslandicus i.e Chrysosporium queenslandicum was reported from Indian soil [18, 24, 26, 38, 39].

The other species of dermatophytes recovered were Trichophyton mentagrophytes (2.00\%) and T. terrestre (3.33\%). Trichophyton mentagrophytes has been reported from Indian soils [26, 34, 40-42] and is known to cause diseases in man and animals $[43,44]$. T. terrestre has been reported from Indian soils by various workers [26, 45-47].

The prevalence of these fungi in the soils of region of Vidarbha is of importance for their pathogenic potential 


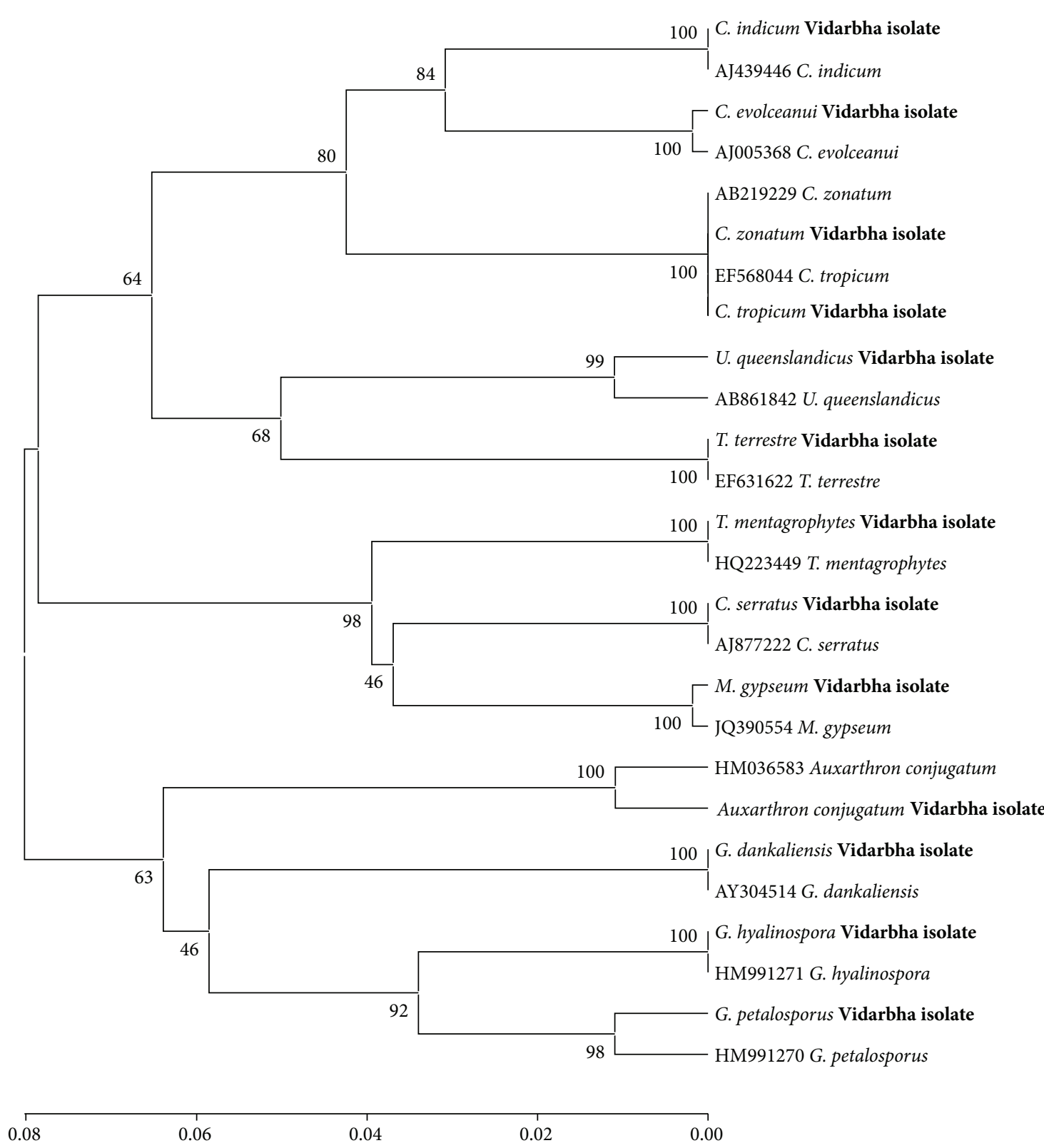

FIgURE 3: Phylogenetic tree based on ITS1-5.8S-ITS4 region sequences for isolated 13 keratinophilic fungi with reference strains. Numbers at the respective nodes are percentage of 1000 bootstrap replicates. Bar indicates genetic distance due to sequence variation.

and has been confirmed in several investigations in different parts of the world. For example, Chrysosporium zonatum was reported to cause disseminated infection in a patient with chronic granulomatous disease [48]. In Japan, C. zonatum strains were isolated from bronchial lavage from a female in Chiba and from a male in Kyushu. Both patients presented pulmonary cavity sites [49]. Chrysosporium tropicum was reported from comb lesion in two different breeds of chicken in India [50]. There are reports of disseminated infections due to C. queenslandicum in garter snakes [51]. Gymnascella dankaliensis was reported from superficial infections in human beings [52] and Iwen et al., [53] isolated Gymnascella hyalinospora from invasive pulmonary infection in a patient with acute myelogenous leukemia. Similarly, Lysková [54] isolated Chrysosporium queenslandicum, C. sulfureum, C. tropicum, Malbranchea pulchella, and Myriodontium keratinophilum from infections of the skin and nails of patients in the Moravian-Silesian Region (Czech Republic). Thus, these fungi may be regarded as opportunistic pathogens.

There are some reports of occurrence of keratinophilic fungi from various parts of Maharashtra [40, 47, 55, 56], but to best of our knowledge, this is the first comprehensive report on incidence of keratinophilic fungi from Vidarbha region. These findings are in agreement with the findings of previous work on keratinophilic fungi. It appears from this study that a rich variety of keratinophilic fungal flora exists 
in Vidarbha region of Maharashtra which may be attributed to the climatic and environmental conditions such as the soil type, vegetation, fauna, and human habitations. Garg et al. [57] emphasized that the climate and perhaps other environmental factors are important in determining the distribution of keratinophilic fungi in ecological habitats.

Our findings confirm the presence of keratinophilic and related dermatophytes in the soils of Vidarbha region. These areas potentially have a high risk for causing cutaneous fungal infections in humans and animals and could be considered as a source of these infections.

\section{Conflict of Interests}

The authors declare that there is no conflict of interests regarding the publication of this paper.

\section{References}

[1] S. K. Deshmukh and S. A. Verekar, "The occurrence of dermatophytes and other keratinophilic fungi from the soils of Himachal Pradesh (India)," Czech Mycology, vol. 58, no. 1-2, pp. 117124, 2006

[2] M. T. Hedayati, A. Mohseni-Bandpi, and S. Moradi, "A survey on the pathogenic fungi in soil samples of potted plants from Sari hospitals, Iran," Journal of Hospital Infection, vol. 58, no. 1, pp. 59-62, 2004.

[3] R. Vanbreuseghem, "Technique biologique pour l'isolement des dermatophytes du sol," Annales de la Societe Belge de Medecine Tropicale, vol. 32, pp. 173-178, 1952.

[4] S. M. Zaki, Y. Mikami, A. A. Karam El-Din, and Y. A. Youssef, "Keratinophilic fungi recovered from muddy soil in Cairo vicinities, Egypt," Mycopathologia, vol. 160, no. 3, pp. 245-251, 2005.

[5] S. K. Deshmukh and S. A. Verekar, "Keratinophilic fungi from the vicinity of meteorite crater soils of Lonar (India)," Mycopathologia, vol. 162, no. 4, pp. 303-306, 2006.

[6] H. C. Gugnani, S. Sharma, and K. Wright, "A preliminary study on the occurrence of keratinophilic fungi in soils of Jamaica," Revista do Instituto de Medicina Tropical de Sao Paulo, vol. 56, no. 3, pp. 231-234, 2014.

[7] K. Pakshir, M. Rahimi Ghiasi, K. Zomorodian, and A. R. Gharavi, "Isolation and molecular identification of keratinophilic fungi from public parks soil in Shiraz, Iran," BioMed Research International, vol. 2013, Article ID 619576, 5 pages, 2013.

[8] L. Sigler and J. W. Carmichael, "Taxonomy of Malbranchea and some other hyphomycetes with arthroconidia," Mycotaxon, vol. 4, pp. 349-488, 1976.

[9] C. A. N. Van Oorschot, "A revision of Chrysosporium and allied genera," Studies in Mycology, vol. 20, pp. 1-89, 1980.

[10] R. S. Currah, "Taxonomy of the Onygenales: Arthrodermaceae, Gymnoascaceae, Myxotrichaceae and Onygenaceae," Mycotaxon, vol. 24, pp. 1-216, 1985.

[11] J. A. von Arx, "The ascomycetes genus Gymnoascus," Persoonia, vol. 13, pp. 173-183, 1986.

[12] J. Cano and J. Gurrao, "The genus Aphanoascus," Mycological Research, vol. 94, pp. 355-377, 1990.

[13] S. B. Lee and J. W. Taylor, "Isolation of DNA from fungal mycelium and single cells," in Protocols: A Guide to Methods and Applications, M. A. Innis, H. D. Gelfand, J. J. Sninsky, and T.
J. White, Eds., pp. 282-287, Academic Press, San Diego, Calif, USA, 1990

[14] T. J. White, T. Bruns, S. Lee, and J. Taylor, "Amplification and direct sequencing of fungal ribosomal RNA genes for phylogenetics," in PCR Protocols: A Guide to Methods and Applications, A. Innis, D. H. Gelfand, J. J. Sninsky, and T. J. White, Eds., pp. 315-322, Academic Press, San Diego, Calif, USA, 1990.

[15] S. F. Altschul, W. Gish, W. Miller, E. W. Myers, and D. J. Lipman, "Basic local alignment search tool," Journal of Molecular Biology, vol. 215, no. 3, pp. 403-410, 1990.

[16] K. Tamura, G. Stecher, D. Peterson, A. Filipski, and S. Kumar, "MEGA6: molecular evolutionary genetics analysis version 6.0," Molecular Biology and Evolution, vol. 30, no. 12, pp. 2725-2729, 2013.

[17] H. S. Randhawa and R. S. Sandhu, "A survey of soil inhabiting dermatophytes and related keratinophilic fungi of India," Sabouraudia Journal of Medical and Veterinary Mycology, vol. 4, no. 2, pp. 71-79, 1965.

[18] S. K. Deshmukh and S. C. Agrawal, "Prevalence of dermatophytes and other keratinophilic fungi in soils of Madhya Pradesh (India)," Mykosen, vol. 26, no. 11, pp. 574-577, 1983.

[19] S. K. Deshmukh and S. A. Verekar, "Prevalence of Keratinophilic fungi in "Usar" Soils of Uttar Pradesh, India," Microbiology Research, vol. 2, no. 2, p. e15, 2011.

[20] S. K. Deshmukh and S. A. Verekar, "Incidence of keratinophilic fungi from the soils of Vedanthangal Water Bird Sanctuary (India)," Mycoses, vol. 54, no. 6, pp. 487-490, 2011.

[21] A. K. Garg, "Isolation of dermatophytes and other keratinophilic fungi from soils in India.," Sabouraudia Journal of Medical and Veterinary Mycology, vol. 4, no. 4, pp. 259-264, 1966.

[22] N. C. Dey and L. M. Kakoti, "Microsporum gypseum in India," Journal of the Indian Medical Association, vol. 25, no. 5, pp. 160164, 1955.

[23] R. K. S. Kushwaha and S. C. Agarwal, "Some keratinophilic fungi and related dermatophytes from soils," Proceedings of the Indian National Science Academy, vol. 42, no. B, pp. 102-110, 1976.

[24] C. J. Singh, B. G. Singh, and B. S. Singh, "Keratinophilic fungi of Ghana birds sanctuary Bharatpur (Rajasthan)," Advances in Plant Sciences, vol. 7, pp. 280-291, 1994.

[25] G. M. Vidyasagar, N. Hosmani, and D. Shivkumar, "Keratinophilic fungi isolated from hospital dust and soils of public places at Gulbarga, India," Mycopathologia, vol. 159, no. 1, pp. 13-21, 2005.

[26] I. Singh, A. Mishra, and R. K. S. Kushwaha, "Dermatophytes, related keratinophilic and opportunistic fungi in indoor dust of houses and hospitals," Indian Journal of Medical Microbiology, vol. 27, no. 3, pp. 242-246, 2009.

[27] N. Jain and M. Sharma, "Distribution of dermatophytes and other related fungi in Jaipur city, with particular reference to soil pH," Mycoses, vol. 54, no. 1, pp. 52-58, 2011.

[28] J. W. Carmichael, "Chrysosporium and some other aleuriosporic hyphomycetes," Canadian Journal of Botany, vol. 40, pp. 11371173, 1962.

[29] S. A. Verekar and S. K. Deshmukh, "Incidence of keratinophilic fungi from caves around Mumbai, Maharastra (India)," Journal of Basic and Applied Mycology, vol. 5, pp. 62-64, 2006.

[30] I. Singh, R. K. S. Kushwaha, and P. Parihar, "Keratinophilic fungi in soil of potted plants of indoor environments in Kanpur, India, and their proteolytic ability," Mycoscience, vol. 50, no. 4, pp. 303307, 2009. 
[31] S. Katiyar and R. K. S. Kushwaha, "Human hair colonizing fungi in water sediments of India," Mycopathologia, vol. 152, no. 2, pp. 81-84, 2001.

[32] I. Singh and R. K. S. Kushwaha, "Dermatophytes and related keratinophilic fungi in soil of parks and agricultural fields of Uttar Pradesh, India," Indian Journal of Dermatology, vol. 55, no. 3, pp. 306-308, 2010.

[33] B. Sur and G. R. Ghosh, "Keratinophilic fungi from Orissa, India I: isolation from soils," Sabouraudia Journal of Medical and Veterinary Mycology, vol. 18, no. 4, pp. 269-274, 1980.

[34] S. K. Deshmukh, "Incidence of keratinophilic fungi from selected soils of Kerala state (India)," Mycopathologia, vol. 156, no. 3, pp. 177-181, 2003.

[35] G. R. Ghosh and S. Bhatt, "Keratinophilic Fungi from Chilka Lake-side Soil Orissa (India)," Indian Journal of Microbiology, vol. 40, no. 4, pp. 247-254, 2000.

[36] P. C. Jain and S. C. Agrawal, "Some additions to Indian Malbranchea," Kavaka, vol. 7, pp. 69-72, 1979.

[37] S. K. Deshmukh and S. C. Agrawal, "Isolation of dermatophytes and other keratinophilic fungi from soils of Jammu, India," Mycoses, vol. 46, no. 5-6, pp. 226-228, 2003.

[38] S. Kaul and G. Sumbali, "Keratinolysis by poultry farm soil fungi," Mycopathologia, vol. 139, no. 3, pp. 137-140, 1997.

[39] P. Saxena, A. Kumar, and J. N. Shrivastava, "Diversity of keratinophilic mycoflora in the soil of Agra (India)," Folia Microbiologica, vol. 49, no. 4, pp. 430-434, 2004.

[40] S. K. Deshmukh, "Isolation of dermatophytes and other keratinophilic fungi from the vicinity of salt pan soils of Mumbai, India," Mycopathologia, vol. 157, no. 3, pp. 265-267, 2004.

[41] H. C. Gugnani, A. Paliwal-Joshi, H. Rahman et al., "Occurrence of pathogenic fungi in soil of burrows of rats and of other sites in bamboo plantations in India and Nepal," Mycoses, vol. 50, no. 6, pp. 507-511, 2007.

[42] M. Sharma and M. Sharma, "Incidence of dermatophytes and other keratinophilic fungi in the schools and college playground soils of Jaipur, India," African Journal of Microbiology Research, vol. 4, no. 24, pp. 2647-2654, 2010.

[43] L. N. Mohapatra, H. C. Gugnani, and K. Shivrajan, "Natural infection in laboratory animals due to Trichophyton mentagrophytes in India," Mycopathologia et Mycologia Applicata, vol. 24, no. 3, pp. 275-280, 1964.

[44] C. A. Oyeka, "Trichophyton mentagrophytes a keratinophilic fungus," in Biology of Dermatophytes and other Keratinophilic Fungi, R. K. S. Kushwaha and J. Guarro, Eds., pp. 60-65, Revista Iberoamericana de Micologia, Bilbao, Spain, 2000.

[45] T. N. Verma, B. K. Sinha, and U. L. Das, "Isolation of keratinophilic fungi from soil in Bihar (India)," Mykosen, vol. 25, no. 8, pp. 449-452, 1982.

[46] S. K. Deshmukh, "Incidence of dermatophytes and other keratinophilic fungi in the glacier bank soils of the Kashmir valley, India," Mycologist, vol. 16, no. 4, pp. 165-167, 2002.

[47] S. K. Deshmukh, "Isolation of dermatophytes and other keratinophilic fungi from Karnala bird sanctuary, Maharashtra (India)," Journal of Basic and Applied Mycology, vol. 1, no. 2, pp. 194-196, 2002.

[48] E. Roilides, L. Sigler, E. Bibashi, H. Katsifa, N. Flaris, and C. Panteliadis, "Disseminated infection due to Chrysosporium zonatum in a patient with chronic granulomatous disease and review of non-aspergillus fungal infections in patients with this disease," Journal of Clinical Microbiology, vol. 37, no. 1, pp. 18-25, 1999.
[49] L. Sigler, A. L. Flis, and J. W. Carmichael, "The genus Uncinocarpus (Onygenaceae) and its synonym Brunneospora: new concepts, combinations and connections to anamorphs in Chrysosporium, and further evidence of relationship with Coccidioides immitis," Canadian Journal of Botany, vol. 76, no. 9, pp. 16241636, 1998.

[50] S. A. Saidi, S. Bhatt, J. L. Richard, A. Sikdar, and G. R. Ghosh, "Chrysosporium tropicum as a probable cause of mycosis of poultry in India," Mycopathologia, vol. 125, no. 3, pp. 143-147, 1994.

[51] T. Vissiennon, K. F. Schüppel, E. Ullrich, and A. F. Kuijpers, "Case report. A disseminated infection due to Chrysosporium queenslandicum in a garter snake (Thamnophis)," Mycoses, vol. 42, no. 1-2, pp. 107-110, 1999.

[52] G. S. de Hoog and J. Guarro, Atlas of Clinical Fungi, Centraalbureau voor Schimmelcultures, Baarn, The Netherlands, 1995.

[53] P. C. Iwen, L. Sigler, S. Tarantolo et al., "Pulmonary infection caused by Gymnascella hyalinospora in a patient with acute myelogenous leukemia," Journal of Clinical Microbiology, vol. 38, no. 1, pp. 375-381, 2000.

[54] P. Lysková, "Saprotrophic microscopic fungi and dermatophytes accompanying infections of the skin and nails of patients in the Moravian-Silesian Region (Czech Republic)," Czech Mycology, vol. 59, pp. 125-137, 2007.

[55] A. A. Padhye, S. P. Misra, and M. J. Thirumalachar, "Occurrence of soil inhabiting dermatophytes and other keratinophilic fungi from soils in Poona," Hindustan Antibiotics Bulletin, vol. 9, no. 2, pp. 90-93, 1966.

[56] A. A. Padhye, V. H. Pawar, R. S. Sukapure, and M. J. Thirumalachar, "Keratinophilic fungi from marine soils of Bombay, India. I.," Hindustan Antibiotics Bulletin, vol. 10, no. 2, pp. 138$141,1967$.

[57] A. P. Garg, S. Gandotra, K. G. Mukerji, and G. J. F. Pugh, "Ecology of keratinophilic fungi," Proceedings: Plant Sciences, vol. 94, no. 2-3, pp. 149-163, 1985. 

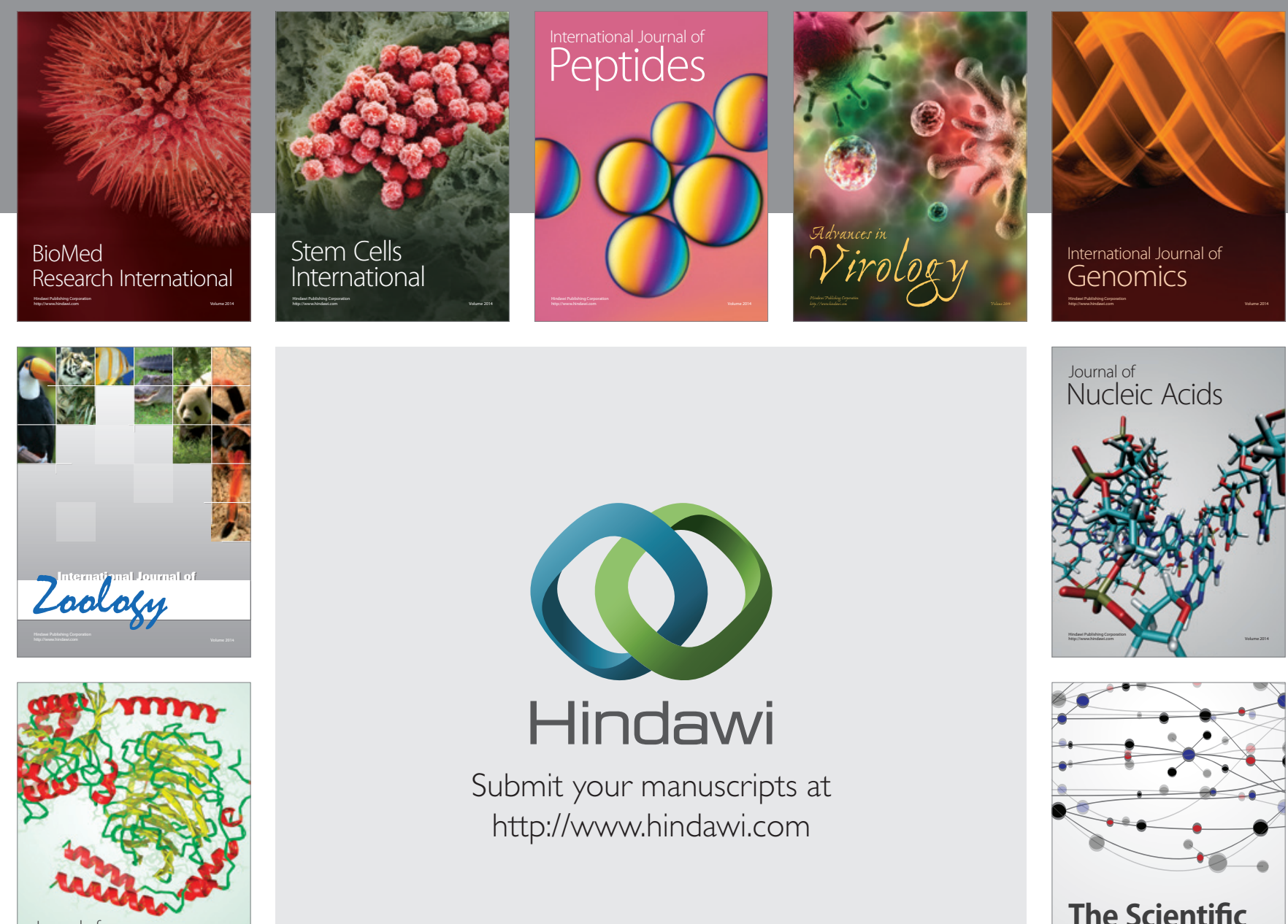

Submit your manuscripts at

http://www.hindawi.com

Journal of
Signal Transduction
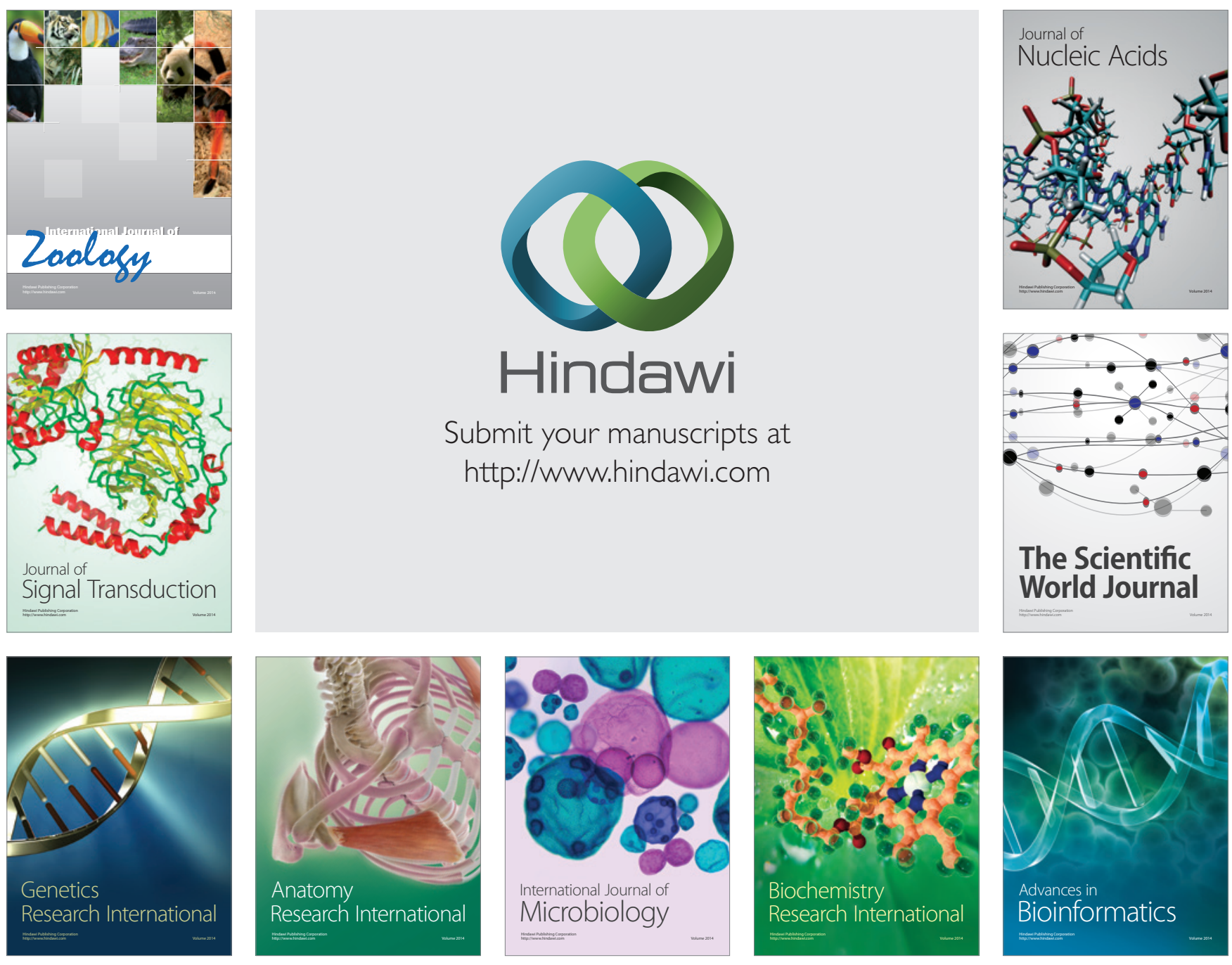

The Scientific World Journal
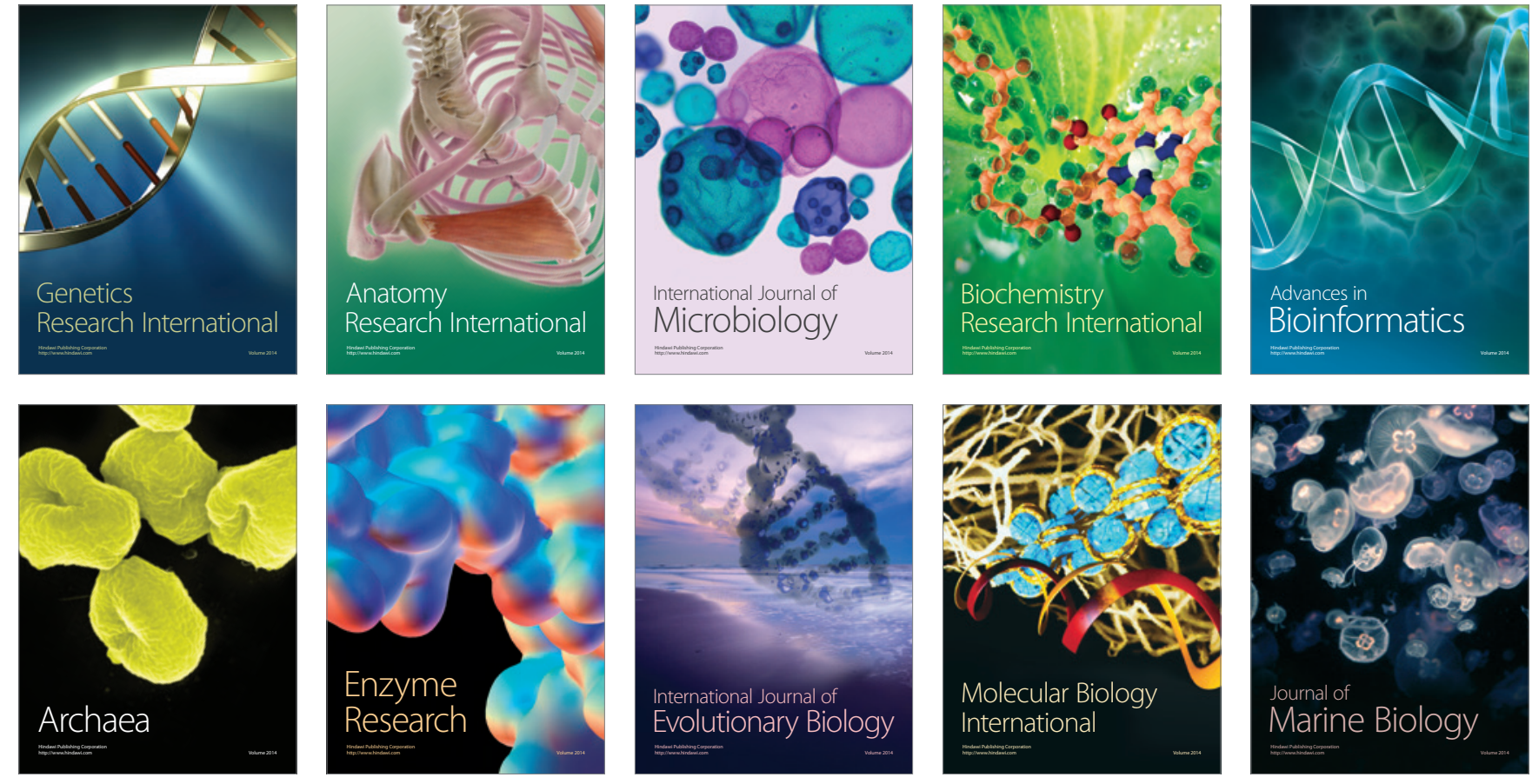